\title{
Comparison of Energy Intakes Estimated by Weighed Dietary Record and Diet History Questionnaire with Total Energy Expenditure Measured by Accelerometer in Young Japanese Women
}

\author{
Kentaro MuraKami ${ }^{1}$, Mari SHIMBO ${ }^{2}$ and Yoko FuKINO ${ }^{2}$ \\ ${ }^{1}$ Department of Food and Nutritional Sciences, Graduate School of Nutritional and Environmental Sciences, \\ and ${ }^{2}$ Department of Nutritional Sciences, School of Food and Nutritional Sciences, \\ University of Shizuoka, Shizuoka 422-8526, Japan
}

(Received April 24, 2004)

\begin{abstract}
Summary In Western countries underestimation of energy intake (EI) is considered a serious problem in dietary surveys, but information on the accuracy of EI among Japanese people is sparse. We compared estimated EI with measured total energy expenditure (TEE) in 21 Japanese women aged 20-22 y. Dietary intake was estimated by 7-d weighed dietary records (7dWR) and a self-administered diet history questionnaire (DHQ). TEE was measured for $25 \pm 3 \mathrm{~d}$ (mean \pm standard deviation, range: 16-27 d) by a uniaxial accelerometer. Both EI by $7 \mathrm{dWR}(1,498 \pm 305 \mathrm{kcal} / \mathrm{d})$ and EI by DHQ $(1,599 \pm 331 \mathrm{kcal} / \mathrm{d})$ were significantly lower than TEE $(1,865 \pm 179 \mathrm{kcal} / \mathrm{d})(p<0.001$ and $p<0.01$, respectively), but neither estimated EI nor the magnitude of EI underestimation $(20 \pm 15 \%$ for $7 \mathrm{dWR}$ and $13 \pm 23 \%$ for $\mathrm{DHQ}$ ) was significantly different between two methods ( $p=0.25$ and $p=0.22$, respectively). The Spearman correlation $(r)$ between TEE and EI was $0.51(p=0.02)$ for $7 \mathrm{dWR}$ and $0.09(p=0.71)$ for DHQ, indicating better ranking of individuals by $7 \mathrm{dWR}$. The accuracy of EI (EI/TEE) was negatively associated with the percentage of EI from protein in $7 \mathrm{dWR}(r=-0.44, p=0.049)$ and positively associated with the percentage of EI from fat in both 7dWR $(r=0.45, p=0.04)$ and DHQ $(r=0.62, p<0.01)$, suggesting selective overestimation of protein and selective underestimation of fat. These results indicate not only underestimation of habitual EI but also selective under- and/or overestimation of macronutrients in both 7dWR and DHQ.
\end{abstract}

Key Words energy intake, dietary assessment method, total energy expenditure, accelerometer, Japanese women

Accurate assessment of habitual dietary intake in free-living populations is an integral component of nutrition research and surveillance activities, and much effort has been spent by responsible researchers to improve methods to estimate food intake of individuals. Nevertheless, underestimation of energy intake (EI: a surrogate measure of total food intake (1)) by a variety of dietary assessment methods relative to total energy expenditure (TEE) measured with the doubly labeled water (DLW) method (the gold standard for measuring free-living TEE $(1,2))$ is common in Western countries (1-3). Additionally, underestimation of EI may happen not randomly in the population but systematically within certain groups of the population. Not only have several factors which are associated with EI underestimation been indicated (3-6), but it appears that a person whose $\mathrm{EI}$ is underestimated on one occasion is likely to have an underestimated EI on other occasions (7). Furthermore, underestimation may not be food and nutrient neutral and may distort the actual balance of foods and nutrients $(3,8-10)$.

In Japan, various dietary assessment methods (particularly dietary record and questionnaire methods) have been used, but information on the accuracy of EI relative to measured TEE among Japanese people is sparse (11). While a few DLW studies have been conducted in elite athletes $(12,13)$ and firefighters (14), no study, to the best of our knowledge, has been published on the accuracy of EI among ordinary Japanese people. Furthermore, because the ways people interpret and respond to dietary assessment methods may be different between Western countries and Japan mainly because of large differences in dietary habits, the accuracy of dietary assessment methods may also be different, making it difficult to extrapolate the findings in Western countries to Japanese people. The aim of the present study, therefore, was to assess the accuracy of EI determined by 7-d weighed dietary records (7dWR) and a self-administered diet history questionnaire (DHQ) in a group of young Japanese women by comparison with TEE measured with a uniaxial accelerometer (ACC). A second aim was to describe characteristics associated with the accuracy of EI and to examine whether or not all foods and nutrients were under- or overestimated to the same degree.

\section{SUBJECTS AND METHODS}

Study design. The present study was conducted on 
students at the School of Food and Nutritional Sciences, University of Shizuoka over a 36-d period between September and November, 2003. The basis of the study was a measurement of TEE by ACC (study days 6-32) with a collection of data on dietary intake using 7dWR (days 5-11) and DHQ (day 8) and on behavioral and psychological characteristics using questionnaires (days 8-12) and anthropometric measurements (days 5, 12, and 33). The subjects were strongly encouraged not to change their dietary habits or lifestyle during the study. The present study was approved by the ethical committee, University of Shizuoka. Written, informed consent was obtained from each student before the study.

Subjects. A pilot study was carried out on a female final-year student. Not only did we find no problem during the pilot study, but the woman also met the inclusion criteria described below; therefore, the results from the pilot study were used in the present analysis. The main study was conducted on 25 third-year students (4 men and 21 women). All the students in the main study as well as the one woman in the pilot study had experience with food recording and calculation of nutrient intake. The inclusion criteria for the present analysis were: having no chronic disease; taking no medication that might affect EI and energy metabolism; not being a current smoker; and being weight stable $( \pm 3.5 \mathrm{~kg})$ for the past 6 mo. According to a questionnaire completed on day 1 , only one woman did not meet all the criteria. We used only the data for the 21 women $(20-22$ y) because of the small number of male participants.

Anthropometry. Height was measured to $0.1 \mathrm{~cm}$ using a standard stadiometer on day 5. Weight (to $0.1 \mathrm{~kg}$ ) and percentage of body fat (\%BF) (to $0.1 \%$ ) were simultaneously measured in normal indoor clothing using a foot-to-foot bioelectrical impedance analyzer (TBF 501, Tanita, Japan) on days 5, 12, and 33. The $\% \mathrm{BF}$ was automatically calculated using the equation supplied by the manufacturer (15). We computed body mass index (BMI) by dividing weight $(\mathrm{kg})$ by height squared $\left(\mathrm{m}^{2}\right)$. For weight, \%BF, and BMI, we used the average values of three measurements. Although we encouraged the subjects to report to a measurement site at 8:30-9:00 am, only 10 of 21 women appeared during the period on all $3 \mathrm{~d}$. In the remaining cases, measurement was performed as soon as the woman appeared.

Accelerometer. TEE was measured with a uniaxial ACC (Select II, Suzuken, Japan). The ACC estimates TEE as the sum of the following three values: basal metabolic rate (BMR) estimated by using sex, age, height, and weight according to the equation for Japanese subjects (16); physical-activity-related energy expenditure (PAEE) that the ACC estimates by monitoring acceleration in the vertical plane; and energy spent for dietinduced thermogenesis $(0.1 \times \mathrm{TEE})$. The sensor to detect acceleration and the principle to estimate TEE in the ACC used are quite similar to those of another uniaxial ACC (Lifecorder, Suzuken) $(17,18)$. The validity of the Lifecorder has been examined in 24 Japanese men against DLW (19) and in 79 Japanese people against whole-body indirect calorimetry (17): the correlation between TEEs by the Lifecorder and the reference was quite high ( $r=0.83$ and $r=0.93$, respectively), although the mean TEE by the Lifecorder was lower than that by the reference ( $20 \%$ and $9 \%$, respectively).

We gave the subjects both verbal and written instructions on how to wear the ACC on day 1. Subjects were requested to wear the ACC on their waist according to the manufacturer's instructions during waking hours except for water activities. They were also asked to record the time when they got up, took the ACC on and off, and went to bed. We issued an ACC to each subject on day 5 after finishing the input of each subject's sex, age, and measured height and weight into the ACC. The ACC was worn by each subject over 27 consecutive d (days 6-32) to theoretically take into account the influence of the menstrual cycle (a standard cycle consists of $28 \mathrm{~d}(20))$ on TEE.

We excluded data for the days when subjects selfreported forgetting to wear the ACC and that contained a value zero of PAEE. The number of days TEE was successfully measured was $24.6 \pm 3.3 \mathrm{~d}$ (mean \pm standard deviation (SD), range: $16-27 \mathrm{~d}$ ), which was not correlated with mean TEE over $16-27 \mathrm{~d}(r=-0.07, p=0.76)$. Also, no significant day-to-day or week-to-week differences in TEE over the $27 \mathrm{~d}$ were observed $(p=0.52$ and $p=0.60$, respectively, data not shown). Thus, we used the mean of eligible measurements for our estimate of TEE. The physical activity level (PAL) was calculated as TEE (estimated by ACC) divided by BMR (estimated in ACC according to the published equation: $\mathrm{BMR}(\mathrm{kcal})=$ 34.3 (standard value for women aged $20-29 \mathrm{y}, \mathrm{kcal} / \mathrm{m}^{2} /$ h) $\times\left[\right.$ weight $^{0.444}(\mathrm{~kg}) \times$ height $\left.^{0.663}(\mathrm{~cm}) \times 88.83 / 10,000\right]$ (body surface area, $\left.\mathrm{m}^{2}\right) \times 24(\mathrm{~h})(16)$ ).

Although 3 of 21 women self-reported at the end of the study that during TEE measurement they became more active than usual as a result of seeing the reading of ACC, their TEE and PAL were not significantly different from those of the other 18 women $(p=0.16$ and $p=0.59$, respectively, data not shown).

$7-d$ weighed dietary records. On day 1 , a dietitian (MS) gave the subjects both written and verbal instructions on how to keep the dietary record with an example of a completed recording sheet. Each subject was issued recording sheets and a digital dietary scale (Minislim 1475, Tanita). Subjects were also instructed on how to weigh each food and drink. We asked the subjects to record all foods and drinks eaten between days 5 and 11 in as much detail as possible. Each item was weighed raw or cooked as available to the subjects with the exception of rice, which was weighed after cooking. When weighing was not possible, subjects described quantities of items using household measures. On days 8 (for the records of days 5-7) and 12 (for the records of days 8-11), the dietitian checked the completeness of food records, and, if necessary, additional information on poorly defined dishes and recipes and unclear items or amounts was obtained by the dietitian or a trained researcher (KM) as soon as possible.

The coding of food records and the conversion of 
other measurements of quantities into grams were performed by the dietitian, who was blind to TEE measurement and the results obtained from DHQ and other questionnaires. Intakes of energy, nutrients, and foods were calculated by the researcher with the supervision of the dietitian using a nutrient calculation program (Basic 4 for Windows, Version 3.0.6, Kagawa Nutrition University, Japan), which was based on the food composition table in Japan (21), and for some of the foods that did not appear in the table data from the nutritional information panel on the food package itself. Intake from dietary supplements was not included. There was no significant day-to-day difference in estimated EI over the $7 \mathrm{~d}(p=0.66$, data not shown), indicating no decline in cooperation over the $7 \mathrm{~d}(4)$; thus, the average intakes of the $7 \mathrm{~d}$ were used.

Although 5 of 21 women self-reported at the end of the study that food recording procedures were timeconsuming and tedious, resulting in changing their diet toward a simpler direction (some indication of underrecording and/or undereating during $7 \mathrm{dWR}$ ), their intakes of energy and macronutrients (percentage of EI $(\% \mathrm{EI})$ ) and the estimation accuracy (EA: EI/TEE) were not significantly different from those in the remaining 16 women ( $p=0.18-0.78$, data not shown).

Self-administered diet history questionnaire. A slightly modified version of a previously validated self-administered DHQ (22-24) was used in the present study. This 16 page questionnaire is designed to capture dietary habits over the past month. The DHQ consists of the following seven sections: dietary behaviors; major cooking methods for fish and shellfish, meat, egg, and vegetables; alcoholic beverages; semi-quantitative frequency of 111 items of foods and drinks; dietary supplement; staple foods (rice, bread, noodles, and other wheat foods) and miso-soup (fermented soy bean paste soup); and open-ended sections for foods consumed regularly ( $\geq$ once per week) but not appearing in the DHQ.

Subjects were asked to answer the DHQ on day 8 under supervision by the researcher and the dietitian. We gave the subjects both verbal and written instructions on how to fill in the DHQ. After collecting the answered questionnaires, we checked if all the questions were completed. When missing values and/or illogical answers were detected, we asked the subjects to complete the questions and/or correct the answers as soon as possible. Energy, nutrient, and food intakes were calculated using an ad hoc computer program (22-24). Information on dietary supplement and foods consumed regularly but not appearing in the DHQ is not used in the calculation (25).

The validity of the test version of the DHQ has previously been evaluated against 3-d diet records (22), a 24-h urinary excretion (23), and serum biomarkers (24). For estimated EI, there was no significant difference between DHQ and 3-d dietary records (7,323 vs. $7,269 \mathrm{~kJ} / \mathrm{d}$ ) and the correlation between these two measurements was moderate $(r=0.48)$ in 47 Japanese women (22). Moreover, relatively plausible mean estimates of EI have been reported among a wide variety of
Japanese subjects (23-26). To our knowledge, however, EI estimated by the DHQ has not been compared with measured TEE.

Questionnaires. On day 8, we distributed to each subject four kinds of self-administered instruments regarding behavioral and psychological characteristics described below (Dutch Eating Behavior Questionnaire (DEBQ) (27), Eating Attitudes Test (EAT) (28), Stunkard-Sørensen silhouettes (29), and Social Desirability Scale (SDS) (30)), which were to be returned on day 12 . We used the Japanese version of each instrument (31-34).

The DEBQ measures restrained eating, emotional eating (excessive eating in response to arousal states such as anger, fear, or anxiety), and external eating (eating in response to food-related stimuli regardless of the actual state of hunger or satiety) and each eating scale has a score 1-5, a higher score indicating increased restrained, emotional, or external eating (27). The EAT assesses the symptoms of eating disorders as a continuous variable and a total score ranges from 26 to 156 , a higher score indicating increased abnormal eating (28). The Stunkard-Sørensen silhouettes are a series of nine drawings of a male or female figure, from extremely thin to obese, which are given a score of $1-9$, respectively (29). Subjects were asked to select the drawings that best represented their perceived body size and the desired body size. A score of body image was then derived from subtracting the score of the desired body size from that of perceived body size; thus, a difference of zero indicates satisfaction while a positive value represents a desire to be thinner. The SDS was used to measure a person's tendency to provide the most socially desirable answer regardless of being or not being the truth (30). This consists of 33 true-false questions and an answer of true in 18 questions and an answer of false in 15 questions are given a score of one. The total score (0-33) is considered a social desirability score and a higher score indicates a stronger tendency to choose the socially desirable answer.

Because the phase of the menstrual cycle may be associated with EI and/or TEE $(20,35,36)$ and hence EA and possibly scores assessed by questionnaires, on day 1 we gave each woman a calendar-like sheet for recording the days menstrual bleeding occurring during the study, which was to be returned at the end of the study (day 36). While 2 of 21 women self-reported an irregular menstrual cycle, the mean of the self-reported cycle length among the remaining 19 women was $28.5 \pm 4.4 \mathrm{~d}$, which was comparable with a standard cycle (28 d) (20). When the onset of menstrual bleeding was considered the end of the luteal phase and the beginning of a new cycle (20), there were no significant differences in EI and EA determined by $7 \mathrm{dWR}$ and the DHQ and behavioral and psychological scores among subjects in the follicular phase (including menses) and those in the luteal phase of the menstrual cycle when each measurement started and those with an irregular menstrual cycle ( $p=0.09-0.73$, data not shown). These findings suggest no influence of the phase of menstrual 
cycle on these variables.

Statistics. The validation of EI against TEE is based on the fundamental principle of energy balance that EI and TEE are equal under the condition of stable body weight $(1,2)$. In the 10 women whose weights were successfully measured during 8:30-9:00 am on all $3 \mathrm{~d}$ and whose physical characteristics (age, height, weight, BMI, and \%BF) were not significantly different from those of the remaining 11 women ( $p=0.20-0.87$, data not shown), a weight loss between days 5 and 12 $(-0.46 \pm 0.60 \mathrm{~kg}$ : some indication of undereating during $7 \mathrm{dWR}$ ) and a weight gain between days 12 and 33 $(+0.20 \pm 0.83 \mathrm{~kg})$ were found, but the weight change between days 5 and 33 was not significantly different from zero $(-0.26 \pm 0.65 \mathrm{~kg}, p=0.24)$. Thus, as the women were considered weight stable during TEE measurement (days 6-32), an EI/TEE ratio of 1.00 was expected.

Data are presented as mean $\pm S D$. The Student's $t$-test for paired samples was used for comparison of EI by each method with TEE and of measures derived from $7 \mathrm{dWR}$ with the corresponding values from the DHQ. To analyze the ability of $7 \mathrm{dWR}$ and the DHQ to rank subjects according to energy needs, the Spearman correlation coefficient $(r)$ was calculated for EI by each method and TEE. To find out if EA was related to subjects' characteristics examined, the Spearman $r$ between EA and each variable was calculated. Selective under- and overestimation of intake of nutrients and foods was also examined by calculating the Spearman $r$ between EA and intake of each nutrient and food. All $p$ values reported are two-sided and $p<0.05$ was considered statistically significant. Statistical analyses were performed using the SPSS for Windows (version 11.5) software program (SPSS Japan Inc.).

\section{RESULTS}

Anthropometric characteristics among 21 women (20.8 \pm 0.5 y, range: $20-22$ y) are shown in Table 1 . Despite a relatively low PAL of the women (1.52 \pm 0.07$)$, TEE $(1,865 \pm 179 \mathrm{kcal} / \mathrm{d})$ was significantly higher than

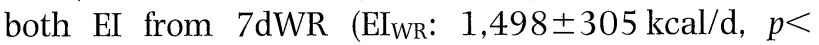
$0.001)$ and $\mathrm{EI}$ from the DHQ (EI $\mathrm{DHQ}_{\mathrm{DQ}}: 1,599 \pm 331 \mathrm{kcal} / \mathrm{d}$, $p<0.01$ ), indicating underestimation of habitual EI by both methods (Table 1). However, neither estimated EI nor the magnitude of EI underestimation (19.7 $\pm 14.5 \%$ for $7 \mathrm{dWR}$ and $13.2 \pm 23.3 \%$ for DHQ) was significantly different between two methods $(p=0.25$ and $p=0.22$, respectively). $\mathrm{EI}_{\mathrm{WR}}$ was significantly associated with TEE $(r=0.51, p=0.02)$ while the correlation between $\mathrm{EI}_{\mathrm{DHQ}}$ and TEE was poor $(r=0.09, p=0.71)$, indicating better ranking of individuals by $7 \mathrm{dWR}$ (Fig. 1).

Table 2 shows the Spearman $r$ between subjects' characteristics examined and EA. The mean scores of

Table 1. Anthropometric measures, total energy expenditure measured with a uniaxial accelerometer, energy intake estimated with 7-d weighed dietary records and a self-administered diet history questionnaire, and estimation accuracy (the ratio of energy intake to total energy expenditure) of both dietary assessment methods in 21 women.

\begin{tabular}{|c|c|c|c|c|c|c|c|c|c|}
\hline \multirow{2}{*}{ Subject } & \multirow{2}{*}{$\begin{array}{l}\text { Height } \\
(\mathrm{cm})\end{array}$} & \multirow{2}{*}{$\begin{array}{c}\text { Weight } \\
(\mathrm{kg})\end{array}$} & \multirow{2}{*}{$\begin{array}{c}\text { BMI } \\
\left(\mathrm{kg} / \mathrm{m}^{2}\right)\end{array}$} & \multirow{2}{*}{$\% \mathrm{BF}$} & \multirow{2}{*}{$\begin{array}{c}\text { TEE } \\
(\mathrm{kcal} / \mathrm{d})\end{array}$} & \multicolumn{2}{|c|}{$\mathrm{EI}(\mathrm{kcal} / \mathrm{d})$} & \multicolumn{2}{|c|}{ EI/TEE } \\
\hline & & & & & & $7 \mathrm{dWR}$ & DHQ & $7 \mathrm{dWR}$ & DHQ \\
\hline 1 & 150.8 & 41.1 & 18.1 & 19.1 & 1,537 & 1,275 & 1,536 & 0.83 & 1.00 \\
\hline 2 & 167.9 & 57.3 & 20.3 & 27.8 & 1,988 & 1,383 & 1,464 & 0.70 & 0.74 \\
\hline 3 & 153.3 & 53.5 & 22.8 & 30.8 & 1,868 & 1,229 & 1,619 & 0.66 & 0.87 \\
\hline 4 & 155.0 & 49.6 & 20.7 & 27.6 & 1,669 & 1,547 & 1,555 & 0.93 & 0.93 \\
\hline 5 & 161.9 & 49.7 & 19.0 & 23.8 & 1,756 & 1,683 & 1,270 & 0.96 & 0.72 \\
\hline 6 & 155.3 & 50.8 & 21.0 & 28.3 & 1,835 & 1,180 & 1,231 & 0.64 & 0.67 \\
\hline 7 & 163.6 & 53.5 & 20.0 & 24.1 & 1,973 & 1,550 & 1,481 & 0.79 & 0.75 \\
\hline 8 & 146.0 & 46.9 & 22.0 & 28.0 & 1,639 & 1,472 & 1,679 & 0.90 & 1.02 \\
\hline 9 & 163.4 & 55.9 & 20.9 & 22.5 & 2,173 & 1,961 & 2,013 & 0.90 & 0.93 \\
\hline 10 & 163.2 & 53.0 & 19.9 & 26.3 & 1,829 & 1,629 & 1,693 & 0.89 & 0.93 \\
\hline 11 & 152.8 & 56.8 & 24.3 & 28.3 & 1,851 & 1,871 & 1,641 & 1.01 & 0.89 \\
\hline 12 & 161.8 & 55.0 & 21.0 & 27.7 & 1,949 & 1,756 & 1,500 & 0.90 & 0.77 \\
\hline 13 & 163.5 & 58.1 & 21.7 & 26.1 & 2,011 & 1,612 & 1,534 & 0.80 & 0.76 \\
\hline 14 & 166.8 & 50.0 & 18.0 & 20.5 & 1,966 & 1,536 & 1,687 & 0.78 & 0.86 \\
\hline 15 & 157.8 & 50.6 & 20.3 & 26.0 & 1,656 & 913 & 1,380 & 0.55 & 0.83 \\
\hline 16 & 162.9 & 58.1 & 21.9 & 26.5 & 2,105 & 1,661 & 1,890 & 0.79 & 0.90 \\
\hline 17 & 156.4 & 55.8 & 22.8 & 31.3 & 1,915 & 1,579 & 1,628 & 0.82 & 0.85 \\
\hline 18 & 169.3 & 63.9 & 22.3 & 27.0 & 2,113 & 1,937 & 1,621 & 0.92 & 0.77 \\
\hline 19 & 159.3 & 52.2 & 20.6 & 26.5 & 1,902 & 765 & 1,191 & 0.40 & 0.63 \\
\hline 20 & 155.1 & 41.6 & 17.3 & 20.6 & 1,544 & 1,344 & 2,725 & 0.87 & 1.76 \\
\hline 21 & 167.2 & 53.1 & 19.0 & 23.5 & 1,886 & 1,579 & 1,232 & 0.84 & 0.65 \\
\hline Mean & 159.7 & 52.7 & 20.7 & 25.8 & 1,865 & 1,498 & 1,599 & 0.80 & 0.87 \\
\hline $\mathrm{SD}$ & 6.2 & 5.4 & 1.8 & 3.2 & 179 & 305 & 331 & 0.15 & 0.23 \\
\hline
\end{tabular}

BMI: body mass index, \%BF: percentage of body fat, TEE: total energy expenditure, EI: energy intake, 7dWR: 7-d weighed dietary records, DHQ: diet history questionnaire, SD: standard deviation. 
(a) $7 \mathrm{dWR}$

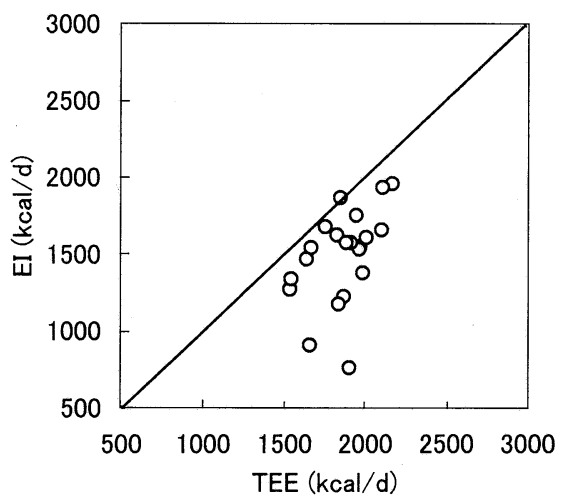

(b) DHQ

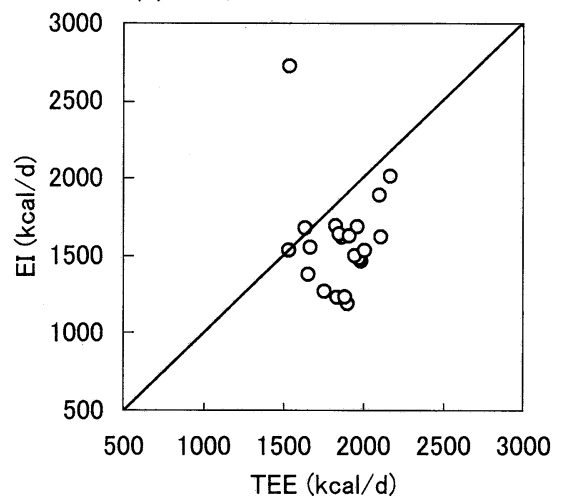

Fig. 1. Relationship of energy intake (EI) in 21 women calculated from two different dietary assessment methods with total energy expenditure (TEE) measured with a uniaxial accelerometer. (a) 7-d weighed dietary records (7dWR). Spearman correlation coefficient $(r)=0.51 \quad(p=0.02)$. (b) Self-administered diet history questionnaire (DHQ). Spearman $r=0.09$ $(p=0.71)$. A straight line is $x=y$.

Table 2. Association of estimation accuracy of 7-d weighed dietary records and a selfadministered diet history questionnaire (the ratio of energy intake to total energy expenditure measured with a uniaxial accelerometer) with selected characteristics among 21 women.

\begin{tabular}{|c|c|c|c|c|}
\hline & \multicolumn{2}{|c|}{$7 \mathrm{dWR}$} & \multicolumn{2}{|c|}{ DHQ } \\
\hline & $r$ & $p$ & $r$ & $p$ \\
\hline \multicolumn{5}{|l|}{ Physical characteristics } \\
\hline Height & -0.10 & 0.67 & -0.53 & 0.01 \\
\hline Weight & 0.02 & 0.95 & -0.32 & 0.16 \\
\hline BMI & 0.12 & 0.62 & 0.02 & 0.92 \\
\hline$\% \mathrm{BF}$ & -0.04 & 0.86 & -0.11 & 0.62 \\
\hline \multicolumn{5}{|l|}{ Behavioral characteristics } \\
\hline Restrained eating (DEBQ) & 0.42 & 0.06 & -0.02 & 0.95 \\
\hline Emotional eating (DEBQ) & 0.13 & 0.56 & 0.16 & 0.48 \\
\hline External eating (DEBQ) & 0.05 & 0.82 & 0.06 & 0.79 \\
\hline EAT & 0.35 & 0.12 & 0.28 & 0.22 \\
\hline \multicolumn{5}{|l|}{ Psychological characteristics } \\
\hline Body image & 0.33 & 0.14 & -0.16 & 0.49 \\
\hline SDS & 0.10 & 0.67 & -0.18 & 0.43 \\
\hline
\end{tabular}

7dWR: 7-d weighed dietary records, DHQ: diet history questionnaire, $r$ : Spearman correlation coefficient, BMI: body mass index, \%BF: percentage of body fat, DEBQ: Dutch Eating Behavior Questionnaire, EAT: Eating Attitudes Test, SDS: Social Desirability Scale.

behavioral and psychological characteristics were as follows: restrained eating 3.3 \pm 0.6 ; emotional eating

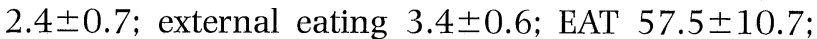
body image 1.1 \pm 0.8 ; SDS $12.0 \pm 4.2$. Only height was significantly associated with EA in the DHQ $(r=-0.53$, $p=0.01$ ).

The associations between EA and the \%EI from macronutrients are shown in Fig. 2. The \%EI from protein, fat, and carbohydrate was respectively 13.6 \pm 1.3 , $28.6 \pm 5.0,56.7 \pm 4.8 \%$ for $7 \mathrm{dWR}$ and $13.5 \pm 1.8$, $28.1 \pm 5.3,56.7 \pm 5.3 \%$ for the DHQ $(p=0.71-0.98)$. We did not calculate the \%EI from alcohol in 7dWR because of only a small number of reports of alcoholic beverages. The \%EI from alcohol estimated by the DHQ was $1.8 \pm 2.1 \%$. For $7 \mathrm{dWR}$, the $\%$ EI from carbohydrate was not significantly related to EA $(r=-0.21, p=0.37)$. However, the \%EI from protein $(r=-0.44, p=0.049)$ and fat $(r=0.45, p=0.04)$ were significantly related to $\mathrm{EA}$; thus, there was an indication for a selective overestimation of protein and a selective underestimation of fat. The \%EI from fat was also selectively underestimated in the DHQ $(r=0.62, p<0.01)$, although the selective misestimation of \%EI from protein $(r=-0.24$, $p=0.30)$, carbohydrate $(r=-0.37, p=0.10)$, and alcohol $(r=-0.17, p=0.45)$ was not observed.

Selective under- or overestimation of intakes (in terms of dietary density) of several micronutrients (including dietary fiber) and foods were also examined (Table 3). For 7dWR, intake of niacin $(r=-0.43$, $p=0.049$ ) was selectively overestimated while intake of 

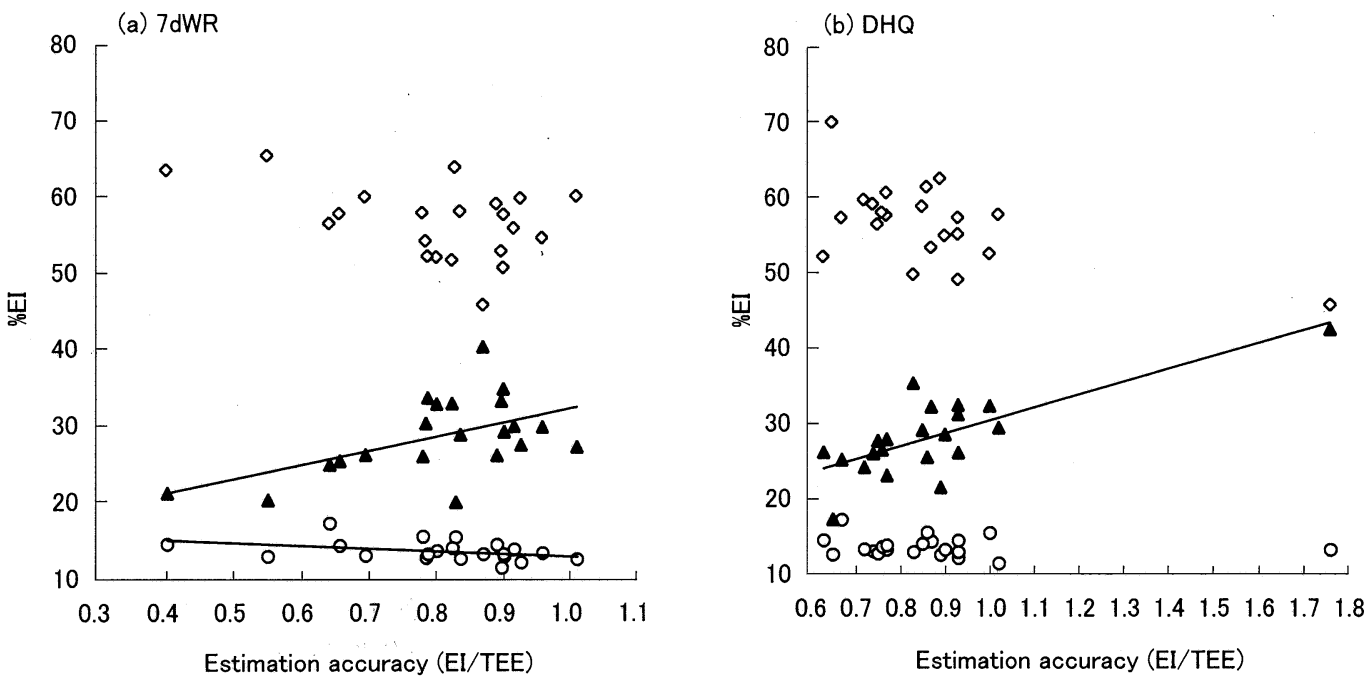

Fig. 2. Estimated percentage of energy intake (\%EI) from macronutrients plotted against estimation accuracy (the ratio of estimated energy intake to total energy expenditure measured with a uniaxial accelerometer (EI/TEE)) among 21 women. (a) 7-d weighed dietary records (7dWR). Spearman correlation coefficient $(r)$ between estimation accuracy and \%EI from each macronutrient is as follows: $r=-0.44$ for protein $(p=0.049), r=0.45$ for fat $(p=0.04)$, and $r=-0.21$ for carbohydrate $(p=0.37)$. (b) Self-administered diet history questionnaire (DHQ). Spearman $r$ between estimation accuracy and \%EI from each macronutrient is as follows: $r=-0.24$ for protein $(p=0.30), r=0.62$ for fat $(p<0.01)$, and $r=-0.37$ for carbohydrate $(p=0.10)$. $\bigcirc$, \%EI from protein; $\mathbf{\Lambda}, \% \mathrm{EI}$ from fat; $\diamond, \% \mathrm{EI}$ from carbohydrate.

Table 3. Relation of estimation accuracy of 7-d weighed dietary records and a self-administered diet history questionnaire (the ratio of energy intake to total energy expenditure measured with a uniaxial accelerometer) to intake of selected nutrients and foods (in terms of dietary density) in 21 women.

\begin{tabular}{|c|c|c|c|c|c|c|}
\hline & \multicolumn{3}{|c|}{ 7dWR } & \multicolumn{3}{|c|}{$\mathrm{DHQ}$} \\
\hline & Mean $\pm S D$ & $r$ & $p$ & Mean $\pm S D$ & $r$ & $p$ \\
\hline \multicolumn{7}{|l|}{ Nutrients } \\
\hline Dietary fiber (g/d/1,000 kcal) & $7.9 \pm 1.6$ & 0.06 & 0.80 & $7.0 \pm 1.3$ & -0.38 & 0.09 \\
\hline Sodium $(\mathrm{mg} / \mathrm{d} / 1,000 \mathrm{kcal})$ & $1,712 \pm 321$ & -0.14 & 0.54 & $1,487 \pm 255$ & -0.13 & 0.59 \\
\hline Potassium (mg/d/1,000 kcal) & $1,281 \pm 226$ & -0.18 & 0.42 & $1,239 \pm 188$ & -0.08 & 0.73 \\
\hline Calcium (mg/d/1,000 kcal) & $335 \pm 94$ & 0.29 & 0.20 & $310 \pm 95$ & 0.17 & 0.45 \\
\hline Iron $(\mathrm{mg} / \mathrm{d} / 1,000 \mathrm{kcal})$ & $4.3 \pm 1.0$ & 0.11 & 0.64 & $3.9 \pm 0.6$ & -0.36 & 0.11 \\
\hline $\operatorname{Vitamin} \mathrm{A}(\mu \mathrm{g} / \mathrm{d} / 1,000 \mathrm{kcal})^{1}$ & $455 \pm 163$ & 0.05 & 0.85 & $432 \pm 163$ & 0.14 & 0.53 \\
\hline Thiamin $(\mathrm{mg} / \mathrm{d} / 1,000 \mathrm{kcal})$ & $0.49 \pm 0.09$ & -0.42 & 0.056 & $0.44 \pm 0.08$ & -0.10 & 0.67 \\
\hline Riboflavin (mg/d/1,000 kcal) & $0.75 \pm 0.21$ & -0.36 & 0.11 & $0.77 \pm 0.16$ & -0.03 & 0.90 \\
\hline $\operatorname{Niacin}(\mathrm{mg} / \mathrm{d} / 1,000 \mathrm{kcal})^{2}$ & $7.0 \pm 1.9$ & -0.43 & 0.049 & $7.3 \pm 1.9$ & -0.14 & 0.54 \\
\hline Vitamin C (mg/d/1,000 kcal) & $51 \pm 24$ & -0.18 & 0.44 & $53 \pm 18$ & -0.11 & 0.65 \\
\hline \multicolumn{7}{|l|}{ Foods (g/d/1,000 kcal) } \\
\hline Dairy products & $103.6 \pm 54.2$ & 0.10 & 0.68 & $123.3 \pm 72.2$ & 0.13 & 0.56 \\
\hline Eggs & $17.5 \pm 10.6$ & -0.14 & 0.55 & $17.8 \pm 10.9$ & -0.24 & 0.29 \\
\hline Fish and shellfish & $14.4 \pm 11.8$ & -0.03 & 0.89 & $26.0 \pm 11.1$ & 0.10 & 0.67 \\
\hline Seaweed & $4.0 \pm 2.4$ & -0.01 & 0.95 & $7.8 \pm 5.4$ & 0.11 & 0.65 \\
\hline Meat & $28.8 \pm 13.5$ & -0.39 & 0.08 & $26.0 \pm 9.0$ & -0.33 & 0.15 \\
\hline Pulses & $27.3 \pm 20.8$ & 0.42 & 0.058 & $26.7 \pm 20.3$ & -0.31 & 0.17 \\
\hline Green and yellow vegetables & $40.0 \pm 21.9$ & 0.00 & 1.00 & $43.0 \pm 19.6$ & 0.11 & 0.65 \\
\hline Other vegetables & $83.3 \pm 40.6$ & 0.34 & 0.13 & $81.1 \pm 34.7$ & -0.19 & 0.41 \\
\hline Mushroom & $7.4 \pm 7.8$ & -0.20 & 0.39 & $6.3 \pm 5.3$ & -0.58 & $<0.01$ \\
\hline Potatoes & $16.1 \pm 11.3$ & -0.16 & 0.50 & $17.3 \pm 11.0$ & 0.12 & 0.61 \\
\hline Fruit & $31.4 \pm 22.8$ & -0.14 & 0.54 & $49.4 \pm 28.7$ & 0.06 & 0.81 \\
\hline Cereals & $206.1 \pm 49.0$ & -0.35 & 0.12 & $223.4 \pm 46.2$ & -0.70 & $<0.001$ \\
\hline Animal fat & $0.3 \pm 0.5$ & -0.15 & 0.52 & $0.3 \pm 0.4$ & -0.05 & 0.82 \\
\hline Vegetable oil & $5.4 \pm 3.1$ & 0.54 & 0.01 & $6.8 \pm 2.8$ & 0.38 & 0.09 \\
\hline Confectionery & $41.4 \pm 22.5$ & 0.42 & 0.058 & $37.1 \pm 17.5$ & 0.30 & 0.19 \\
\hline
\end{tabular}

7dWR: 7-d weighed dietary records, DHQ: diet history questionnaire, SD: standard deviation, $r$ : Spearman correlation coefficient.

${ }^{1}$ Retinol equivalents.

${ }^{2}$ Niacin equivalents. 
vegetable oil ( $r=0.54, p=0.01)$ was selectively underestimated. For DHQ, none of the intakes of micronutrients examined were selectively under- or overestimated although intakes of mushroom $(r=-0.58, p<0.01)$ and cereals $(r=-0.70, p<0.001)$ were selectively overestimated. Thus, although only a few associations reached statistical significance, the possibility that all foods and nutrients are under- or overestimated to the same degree may be quite low in both dietary assessment methods used.

\section{DISCUSSION}

We are aware of no published reports that describe the accuracy of EI relative to measured TEE in ordinary Japanese people. We found that both $7 \mathrm{dWR}$ and the DHQ underestimated habitual EI compared with measured TEE in a group of young Japanese women, while $7 \mathrm{dWR}$ was able to better rank subjects' EI compared to TEE than was the DHQ. Furthermore, it appeared to be quite unlikely that all foods and nutrients were proportionally underestimated in both methods used.

Our estimates of EI are within the range of EI usually obtained in dietary surveys in young Japanese women. Using dietary records, some studies have reported higher mean EI (1,687-1,800 kcal/d (37-39)), but others similar or lower mean EI $(1,336-1,533 \mathrm{kcal} / \mathrm{d}$ (40-42)) compared with our estimate of EI $\mathrm{WR}_{\mathrm{W}}(1,499$ $\mathrm{kcal} / \mathrm{d})$. For the DHQ, our estimate of EI $(1,599 \mathrm{kcal} / \mathrm{d})$ was lower than EI reported in several studies $(1,822-$ $1,877 \mathrm{kcal} / \mathrm{d}(23,26))$ but comparable with EI reported in a study $(1,536 \mathrm{kcal} / \mathrm{d}(25))$.

The main limitation of the present study is that we measured TEE using a previously validated ACC instead of the DLW because of disadvantages of the DLW including its high cost. As mentioned previously, it is quite likely that the ACC underestimates TEE $(17,19)$. Moreover, because we excluded only data of days when subjects self-reported forgetting to wear ACC and that contained a value zero of PAEE, we may have included days when the ACC was not worn during periods of activity. Actually, mean PAL in the present study (1.52) was lower than not only values in normally active freeliving women aged $18-74 \mathrm{y}$ in Western countries (1.62-1.70) (43) but also a value for sedentary lifestyle (1.56) (44). Thus, it is highly probable that TEE is underestimated in the present study; consequently, the magnitude of EI underestimation $(20 \%$ for $7 \mathrm{dWR}$ and $13 \%$ for DHQ) may also be underestimated.

However, satisfactorily high correlations between measures of TEE by the ACC and reference methods have been reported $(17,19)$, as mentioned previously; therefore, we persisted in correlation analyses to examine factors associated with EA and selective under- and overestimation of nutrient and food intake rather than dividing subjects into people with accurate EA and those with inaccurate EA and comparing these subgroups (9). We also used the correlation coefficient to examine the ability of $7 \mathrm{dWR}$ and the DHQ to rank individuals according to TEE.

Many studies of women in Western countries have shown EI underestimation compared with TEE measured by the DLW using both dietary records (11-20\%) $(4,5,45-47)$ and food frequency or diet history questionnaires (10-38\%) $(3,5,6,48,49)$. In Japan, underestimation of EI by dietary records relative to TEE by the DLW (12-23\%) has also been observed in a small group of elite athletes $(12,13)$ and firefighters $(14)$. Although direct comparison of the magnitude of EI underestimation between these previous studies and the present study may be difficult mainly because we measured TEE using an ACC instead of the DLW, we also found EI underestimation by both $7 \mathrm{dWR}$ and the DHQ.

Given the burden of recording all foods and drinks consumed during $7 \mathrm{~d}$, EI underestimation in $7 \mathrm{dWR}$ may not be surprising. EI underestimation in $7 \mathrm{dWR}$ is considered to be due to underrecording and/or undereating. However, although there were some indications of both underrecording (based on self-report) and undereating (based on self-report and weight loss), the magnitude of contribution of underrecording and undereating to EI underestimation could not be quantified in the present study, which should be examined in future research.

Also, EI underestimation in the DHQ may not be surprising not only because dietary questionnaires measure only memory and perception of usual diet not actual diet and (semi-quantitatively) assess only a limited number of food items, but also because the purpose of the dietary questionnaire method is typically qualitative assessments of dietary patterns rather than measuring absolute intake of individuals (50). However, while almost all dietary questionnaires in Japan have been compared with only another dietary assessment method such as dietary records, we examined the accuracy of EI determined from one of the most widely validated questionnaires (22-24).

While the correlation between EI and TEE by the DLW observed in previous studies of women ranges from low to moderate in both dietary records $(0.13$ $0.48)(4,5,45-47)$ and dietary questionnaires $(0.06-$ $0.48)(3,5,6,48,49)$, 7dWR appeared to perform better in ranking individuals for $\mathrm{EI}$ according to TEE $(r=0.51)$ than did the DHQ $(r=0.09)$ in the present study. This may not be surprising given the nature and limitation of the dietary questionnaire method described above. However, there was substantial variability in EA in both 7dWR (0.40-1.01) and the DHQ (0.63-1.76) at the individual level. Moreover, EIs of 4 of 21 women were consistently underestimated by $>20 \%$ in both $7 \mathrm{dWR}$ and DHQ while EAs of 7 of 21 women were consistently within 0.80 to 1.20 in both methods, suggesting that subjects with underestimated (relatively accurate) EI at one occasion also tend to have underestimated (relatively accurate) EI even if different methods are used. Similar findings have also been reported in previous studies (7). Thus, there seem to be some people from which researchers have more difficulty in obtaining accurate dietary intake data than from others.

Many studies in Western countries have indicated a variety of factors associated with EA including BMI 
and/or \%BF (3, 4), eating behavior (5), body image (51), and social desirability $(4,6,51)$. Also, EI from the DHQ has not significantly correlated with BMI ( $r=-0.04$ ) among 1,695 young Japanese women, suggesting underestimation of EI by obese subjects (52). By contrast, in the present study EA was not related to any of these factors while only height was significantly related to EA in the DHQ $(r=-0.53)$. To our knowledge, a negative association between the ratio of EI to TEE by the DLW and height was observed only in a small study of 16 Swedish girls using the diet history interview (9). The reason for this association is unknown; however, it might be suggested that tall women tended to underreport frequencies and/or quantities of foods they usually eat to a greater extent than other women in the present and the previous (9) studies.

If all foods and nutrients were underestimated to the same degree when EI was underestimated, the solution would be relatively simple because such techniques as energy adjustment should improve estimates of food and nutrient intakes (53). Unfortunately, we found selective under- and overestimation of macronutrients: as EI underestimation increased \%EI from protein increased in $7 \mathrm{dWR}$ while \%EI from fat decreased in both $7 \mathrm{dWR}$ and the DHQ. Furthermore, intake of niacin increased as EI underestimation increased in $7 \mathrm{dWR}$. Selective under- and overestimation of macronutrients has also been indicated in several DLW studies $(3,9)$. The \%EI from fat was inversely related to the percentage of EI underestimation among 30 obese men, indicating selective underestimation of fat $(8)$. Selective underestimation of fat and selective overestimation of protein were also observed in 64 older people (10). These findings may have a substantial impact on studies of diet and health because misleading conclusions with regard to diet and health may be drawn due to selective misestimation of dietary intake (54).

Since the primary measure is food intake in dietary assessment, selective under- and overestimation of nutrients inevitably results from selective under- and overestimation of foods (1). We observed selective underestimation of vegetable oil in 7dWR and selective overestimation of cereals and mushroom in DHQ. In addition, a wide range of the absolute value of the Spearman $r$ between EA and intake of each food in both $7 \mathrm{dWR}(0.00-0.54)$ and the DHQ (0.05-0.70) suggests that there are some foods relatively accurately estimated and others inaccurately estimated. Although information on selective under- and overestimation of foods is limited (9), researchers must understand which foods are likely to be under- or overestimated and which foods are not if dietary assessment methods are to be improved.

Substantial underestimation of EI in both 7dWR and the DHQ in a group of women studying food and nutrition and having experience of food recording we observed suggests that it is unlikely that people who are familiar with recording food intake are less prone to estimation bias than are people drawn from the general population. Similar findings of EI underestimation by dietary records relative to TEE by the DLW (10-20\%) have also been reported in female dietitians (55) and women with extensive training and experience of food recording $(4,45)$.

As the subjects are students studying food and nutrition, they are quite different from the general population, making it difficult to generalize our findings. Note that, however, mean BMI of the subjects $(20.7 \pm 1.8 \mathrm{~kg} /$ $\mathrm{m}^{2}$ ) was comparable with that of 435 women aged 20$29 \mathrm{y}$ in the National Nutrition Survey in Japan, 2002 $\left(20.4 \pm 3.0 \mathrm{~kg} / \mathrm{m}^{2}\right)(56)$.

In conclusion, both $7 \mathrm{dWR}$ and the DHQ underestimated habitual EI compared with measured TEE in a group of young Japanese women, while $7 \mathrm{dWR}$ appeared to perform better than the DHQ in ranking individuals. Additionally, selective overestimation of protein intake in $7 \mathrm{dWR}$ and selective underestimation of fat intake in both $7 \mathrm{dWR}$ and the DHQ were observed, suggesting that not all foods and nutrients were likely to be underestimated to the same degree in both methods. Because little information on the accuracy of EI and selective under- and overestimation of dietary intake in Japanese people is available at present (11), additional research on various dietary assessment methods such as 24-h dietary recall and other dietary questionnaires is needed for other groups including children and adolescents, middle-aged, and elderly people as well as male subjects to better understand and improve the accuracy of dietary assessment methods for Japanese people.

\section{Acknowledgments}

We are grateful to the subjects for their cooperation. This project was supported by a special grant from the University of Shizuoka.

KM was responsible for the concept and design of the study and collection of all data except for those derived from dietary records, analyzed and interpreted the data, and wrote the manuscript. MS was involved in the concept and design of the study, data collection, and discussion and interpretation of results and was responsible for collection of data and calculations derived from dietary records. YF was responsible for seeking the ethical approval for the study, recruiting subjects, and obtaining informed consent, and was involved in data collection.

\section{REFERENCES}

1) Livingstone MBE, Black AE. 2003. Markers of the validity of reported energy intake. J Nutr 133: 895S-920S.

2) Hill RJ, Davies PSW. 2001. The validity of self-reported energy intake as determined using the doubly labelled water technique. Br J Nutr 85: 415-430.

3) Subar AF, Kipnis V, Troiano RP, Midthune D, Schoeller DA, Bingham S, Sharbaugh CO, Trabulsi J, Runswick S, Ballard-Barbash R, Sunshine J, Schatzkin A. 2003. Using intake biomarkers to evaluate the extent of dietary misreporting in a large sample of adults: the OPEN Study. Am J Epidemiol 158: 1-13.

4) Taren DL, Tobar M, Hill A, Howell W, Shisslak C, Bell I, Ritenbaugh C. 1999. The association of energy intake bias with psychological scores of women. Eur J Clin Nutr 
53: $570-578$

5) Bathalon GP, Tucker KL, Hays NP, Vinken AG, Greenberg AS, McCrory MA, Roberts SB. 2000. Psychological measures of eating behavior and the accuracy of $3 \mathrm{com}-$ mon dietary assessment methods in healthy postmenopausal women. Am J Clin Nutr 71: 739-745.

6) Hebert JR, Ebbeling CB, Matthews CE, Hurley TG, Ma Y, Druker S, Clemow L. 2002. Systematic errors in middleaged women's estimates of energy intake: comparing three self-report measures to total energy expenditure from doubly labeled water. Ann Epidemiol 12: 577-586.

7) Black AE, Cole TJ. 2001. Biased over- or under-reporting is characteristic of individuals whether over time or by different assessment methods. J Am Diet Assoc 101: 70-80.

8) Goris AHC, Westerterp-Plantenga MS, Westerterp KR. 2000. Undereating and underrecording of habitual food intake in obese men: selective underreporting of fat intake. Am J Clin Nutr 71: 130-134.

9) Sjöberg A, Slinde F, Arvidsson D, Ellegård L, Gramatkovski E, Hallberg L, Hulthén L. 2003. Energy intake in Swedish adolescents: validation of diet history with doubly labelled water. Eur J Clin Nutr 57: 1643-1652.

10) Tomoyasu NJ, Toth MJ, Poehlman ET. 2000. Misreporting of total energy intake in older African Americans. Int J Obes Relat Metab Disord 24: 20-26.

11) Murakami K. 2004. Critical examination of reported energy intake in published dietary studies of Japanese subjects using the Goldberg cut-off. J Nutr Sci Vitaminol 50: $165-170$.

12) Ebine N, Feng JY, Homma M, Saitoh S, Jones PJH. 2000. Total energy expenditure of elite synchronized swimmers measured by the doubly labeled water method. Eur J Appl Physiol 83: 1-6.

13) Ebine N, Rafamantanantsoa HH, Nayuki Y, Yamanaka K, Tashima K, Ono T, Saitoh S, Jones PJH. 2002. Measurement of total energy expenditure by the doubly labelled water method in professional soccer players. J Sports Sci 20: 391-397.

14) Touno M, Rafamantanantsoa HH, Ebine N, Peng HY, Yoshitake Y, Tanaka H, Saitoh S. 2003. Measurement of total energy expenditure in Japanese firefighters under normal working condition using the doubly labeled water method. Tairyoku Kagaku (Jpn J Phys Fitness Sports Med) 52: 265-274 (in Japanese with English summary).

15) Sakamoto N, Sakamoto Y. 1997. Usefulness for measurement of body fat by standing-bipedal type impedance fat analyzer. Tokyo Jikeikai Ika Daigaku Zasshi (Tokyo Jikeikai Med J) 112: 681-695 (in Japanese with English summary).

16) Health Promotion and Nutrition Division, Health Service Bureau, Ministry of Health and Welfare, Japan. 1994. Recommended Dietary Allowances for the Japanese, 5th ed. Daiichi Shuppan, Tokyo (in Japanese).

17) Kumahara H, Schutz Y, Ayabe M, Yoshioka M, Yoshitake Y, Shindo M, Ishii K, Tanaka H. 2004. The use of uniaxial accelerometry for the assessment of physical-activity-related energy expenditure: a validation study against whole-body indirect calorimetry. Br J Nutr 91: 235-243.

18) Higuchi H, Ayabe M, Shindo M, Yoshitake Y, Tanaka H. 2003. Comparison of daily energy expenditure in young and older Japanese using pedometer with accelerometer. Tairyoku Kagaku (Jpn J Phys Fitness Sports Med) 52:
111-118 (in Japanese with English summary).

19) Rafamantanantsoa HH, Ebine N, Yoshioka M, Higuchi H, Yoshitake Y, Tanaka H, Saitoh S, Jones PJH. 2002. Validation of three alternative methods to measure total energy expenditure against the doubly labeled water method for older Japanese men. J Nutr Sci Vitaminol 48: $517-523$.

20) Buffenstein R, Poppitt SD, McDevitt RM, Prentice AM. 1995. Food intake and the menstrual cycle: a retrospective analysis, with implications for appetite research. Physiol Behav 58: 1067-1077.

21) Science and Technology Agency, Japan. 2000. Standard Tables of Food Composition in Japan, 5th revised ed. Printing Bureau of the Ministry of Finance, Tokyo (in Japanese).

22) Sasaki S, Yanagibori R, Amano K. 1998. Self-administered diet history questionnaire developed for health education: a relative validation of the test-version by comparison with 3-day diet record in women. J Epidemiol 8: 203-215.

23) Sasaki S, Yanagibori R, Amano K. 1998. Validity of a self-administered diet history questionnaire for assessment of sodium and potassium - comparison with single 24-hour urinary excretion-. Jpn Circ J 62: 431435.

24) Sasaki S, Ushio F, Amano K, Morihara M, Todoriki T, Uehara Y, Toyooka T. 2000. Serum biomarker-based validation of a self-administered diet history questionnaire for Japanese subjects. J Nutr Sci Vitaminol 46: 285-296.

25) Sasaki S, Tsuji T. 2003. Influence of co-habitation on a family line resemblance in nutrient and food-group intake among three generations of Japanese women. J Community Nutr 5: 93-104 (This article has first been published in Eiyogaku Zasshi (Jpn J Nutr) 2000; 58: 195-206 (in Japanese)).

26) Sasaki S, Tsuji T, Katagiri A, Shimoda T, for the Diets of the Fresh Students in Dietetic Courses Study Group. 2000. Association between the number of food items bought in convenience stores and nutrient and foodgroup intakes-a survey of first-year female college students taking dietetic courses-. Nippon Eiyo Shokuryo Gakkaishi (J Jpn Soc Nutr Food Sci) 53: 215-226 (in Japanese with English summary).

27) van Strien T, Frijters JER, Bergers GPA, Defares PB. 1986. The Dutch Eating Behavior Questionnaire (DEBQ) for assessment of restrained, emotional, and external eating behavior. Int J Eat Disord 5: 295-315.

28) Garner DM, Olmsted MP, Bohr Y, Garfinkel PE. 1982. The Eating Attitudes Test: psychometric features and clinical correlates. Psychol Med 12: 871-878.

29) Stunkard AJ, Sørensen T, Schulsinger F. 1983. Use of the Danish adoption resister for the study of obesity and thinness. In: Genetics of Neurological and Psychiatric Disorders (Kety SS, Rowland LP, Sidman RL, Matthysse SW, eds), p 115-120. Raven Press, New York.

30) Crowne DP, Marlowe D. 1960. A new scale of social desirability independent of psychopathology. I Consult Psychol 24: 349-354.

31) Imada S. 1994. Psychological studies about eating behavior (3): a Japanese version of the Dutch Eating Behavior Questionnaire (DEBQ). Hiroshima Syudai Ronsyu, Jinbun Hen 34: 281-291 (in Japanese with English summary).

32) Mukai T, Crago M, Shisslak CM. 1994. Eating attitudes 
and weight preoccupation among female high school students in Japan. J Child Psychol Psychiatry 35: 677688.

33) Mukai T. 1996. Body dissatisfaction, depressive affect and eating problems among young adolescent girls: a prospective study. Kaunseringu Kenkyu (Jpn J Couns Sci) 29: 37-43 (in Japanese with English summary).

34) Kitamura T, Suzuki T. 1986. Japanese version of Social Desirability Scale. Shakai Seishin Igaku (Jpn J Soc Psychiatry) 9: 173-180 (in Japanese).

35) Webb P. 1986. 24-hour energy expenditure and the menstrual cycle. Am J Clin Nutr 44: 614-619.

36) Bisdee JT, James WPT, Shaw MA. 1989. Changes in energy expenditure during the menstrual cycle. $\mathrm{Br} J$ Nutr 61: 187-199.

37) Nakashima Y. 1994. Relationship between body composition and energy balance and dietary pattern of female students. Eiyogaku Zasshi (Jpn J Nutr) 52: 227-235 (in Japanese with English summary).

38) Kimura T, Kagaya M, Fukuya Y. 1992. Survey on life style and dietary pattern of female college students and their mothers. Eiyogaku Zasshi (Jpn J Nutr) 50: 325-336 (in Japanese with English summary).

39) Okazaki M, Nakamura S, Oku T. 1998. Relationship between dietary fiber and lipid intake in young and elderly women in a large city. Nippon Eiyo Shokuryo Gakkaishi (J Jpn Soc Nutr Food Sci) 51: 47-55 (in Japanese with English summary).

40) Aikawa R, Hikosaka R, Kondo I, Yaguramaki K. 2001. A study of lifestyle and dietary intake of female college students in Tokyo-the relationship between food intake and situation of life in students tending to masked obesity—. Eiyogaku Zasshi (Jpn J Nutr) 59: 147155 (in Japanese).

41) Date C, Yamaguchi M, Tanaka H. 1996. Development of a food frequency questionnaire in Japan. J Epidemiol 6: S131-S136.

42) Wang DH, Kogashiwa M, Ohta S, Kira S. 2002. Validity and reliability of a dietary assessment method: the application of a digital camera with a mobile phone card attachment. J Nutr Sci Vitaminol 48: 498-504.

43) Black AE, Coward WA, Cole TJ, Prentice AM. 1996. Human energy expenditure in affluent societies: an analysis of 574 doubly-labelled water measurements. Eur J Clin Nutr 50: 72-92.

44) $\mathrm{FAO} / \mathrm{WHO} / \mathrm{UNU}$. 1985. Energy and protein requirements. Report of a Joint FAO/WHO/UNU Expert Consultation, Technical Report Series 724. World Health Organization, Geneva.

45) Martin LJ, Su W, Jones PJ, Lockwood GA, Tritchler DL, Boyd NF. 1996. Comparison of energy intakes determined by food records and doubly labeled water in women participating in a dietary-intervention trial. $\mathrm{Am}$
J Clin Nutr 63: 483-490.

46) Black AE, Bingham SA, Johansson G, Coward WA 1997. Validation of dietary intakes of protein and energy against 24 hour urinary N and DLW energy expenditure in middle-aged women, retired men and post-obese subjects: comparisons with validation against presumed energy requirements. Eur J Clin Nutr 51: 405-413.

47) Black AE, Welch AA, Bingham SA. 2000. Validation of dietary intakes measured by diet history against $24 \mathrm{~h}$ urinary nitrogen excretion and energy expenditure measured by the doubly-labelled water method in middle-aged women. Br J Nutr 83: 341-354.

48) Kroke A, Klipstein-Grobusch K, Voss S, Möseneder J, Thielecke F, Noack R, Boeing H. 1999. Validation of a self-administered food-frequency questionnaire administered in the European Prospective Investigation into Cancer and Nutrition (EPIC) Study: comparison of energy, protein, and macronutrient intakes estimated with the doubly labeled water, urinary nitrogen, and repeated 24-h dietary recall methods. Am J Clin Nutr 70: $439-447$.

49) Andersen LF, Tomten H, Haggarty P, Løvø A, Hustvedt BE. 2003. Validation of energy intake estimated from a food frequency questionnaire: a doubly labelled water study. Eur J Clin Nutr 57: 279-284.

50) Willett W, Stampfer MJ. 1986. Total energy intake: implications for epidemiologic analyses. Am J Epidemiol 124: 17-27.

51) Novotny JA, Rumpler WV, Riddick H, Hebert JR, Rhodes D, Judd JT, Baer DJ, McDowell M, Briefel R. 2003. Personality characteristics as predictors of underreporting of energy intake on 24-hour dietary recall interviews. J Am Diet Assoc 103: 1146-1151.

52) Sasaki S, Katagiri A, Tsuji T, Shimoda T, Amano K. 2003. Self-reported rate of eating correlates with body mass index in 18-y-old Japanese women. Int J Obes Relat Metab Disord 27: 1405-1410.

53) Johnson RK. 2002. Dietary intake-how do we measure what people are really eating? Obes Res 10: 63S$68 \mathrm{~S}$.

54) Trabulsi J, Schoeller DA. 2001. Evaluation of dietary assessment instruments against doubly labeled water, a biomarker of habitual energy intake. Am J Physiol Endocrinol Metab 281: E891-E899.

55) Champagne CM, Bray GA, Kurtz AA, Monteiro JBR, Tucker E, Volaufova J, Delany JP. 2002. Energy intake and energy expenditure: a controlled study comparing dietitians and non-dietitians. J Am Diet Assoc 102 : 1428-1432.

56) Kenko Eiyo Joho Kenkyukai. 2004. The National Nutrition Survey in Japan, 2002. Daiichi Shuppan, Tokyo (in Japanese). 